\title{
Lead Time for Cities of Northern India by Using Multiparameter EEW Algorithm
}

\author{
Rakhi Bhardwaj (iD) and Mukat Lal Sharma ${ }^{2}$ \\ ${ }^{1}$ Department of Electronics and Communication Engineering, GNIOT, Greater Noida 201308, Greater Noida, India \\ ${ }^{2}$ Department of Earthquake engineering, Indian Institute of Technology Roorkee, Roorkee 247667, Uttarakhand, India \\ Correspondence should be addressed to Rakhi Bhardwaj; rakhibhardwaj25@gmail.com
}

Received 12 May 2018; Accepted 12 September 2018; Published 26 September 2018

Guest Editor: ZhiQiang Chen

Copyright (c) 2018 Rakhi Bhardwaj and Mukat Lal Sharma. This is an open access article distributed under the Creative Commons Attribution License, which permits unrestricted use, distribution, and reproduction in any medium, provided the original work is properly cited.

\begin{abstract}
Earthquake early warning (EEW) is considered one of the important real-time earthquake damage mitigation measures. The presence of seismogenic sources generating high seismicity in Himalayas and the cities of concern lying at appropriate distances makes Northern India a perfect case to be monitored using EEW systems. In the present study, an attempt has been made to estimate the lead times for Northern Indian cities for issuing early warning by using the EEW system deployed by IIT Roorkee in Central Himalayas. The instrumentation deployed at 100 locations between Uttarkashi and Chamoli has been used to estimate the lead time at six cities. The estimated lead time includes the time to reach S-wave after subtraction of the sum of P-wave arrival time at the station, time taken by EEW algorithm, transmission and processing delay. The study reveals that for Dehradun, Hardwar, Roorkee, Muzaffarnagar, Meerut, and Delhi the minimum calculated lead time is 5, 11, 20, 35, and $68 \mathrm{sec}$ while the maximum lead time is 37, $36,47,59$, and $90 \mathrm{sec}$, respectively. Such larger estimated lead times to these densely populated cities show that EEW can successfully work as one of the important real-time earthquake disaster reduction measures in Northern India.
\end{abstract}

\section{Introduction}

The rapid growth of the world's population over the past few decades has led to a concentration of people, buildings, and infrastructure in urban areas. These vulnerable areas when falling in vicinity of seismically active sources become the center of disasters in terms of economic losses and death tolls. Such a case exists in Northern India where a lot of development has taken place in the vicinity of Himalayas which is one of the world's seismically very active zone. Himalaya has been repeatedly hit by damaging earthquakes including some of the great earthquakes, namely, 1897 Shilong (M 8.7), 1905 Kangra (M 8.6), 1934 Bihar (M 8.4), and 1950 Assam (M 8.7), along with other moderate earthquakes which occurred recently, for example, 1991 Uttarkashi (M 6.8), 1999 Chamoli (M 6.4), 2005 Muzaffarabad (M 7.6), and 2011 Sikkim earthquake (M 6.9) in which huge loss of life and property took place [1-3]. The recent $2015 \mathrm{Nepal}$ earthquake may be considered as a whistle blower for revisiting our preparedness towards heavy losses which the local populace has to face in future due to such natural calamity. The problem becomes manifold when the pace of urbanization rapidly increases into the Himalayan region and its periphery and, in turn, increase in the vulnerability is considered. It is therefore essential to take measures to reduce earthquake losses through scientific research. In addition, to create an earthquake resilience society by providing earthquake resistant built environment, it will be of paramount importance to consider the information about such event if it can be given a priori. Since earthquake prediction seems to be a little distant future, the earthquake early warning (EEW) systems are making swift in-roads in becoming a practical tool to reduce the losses by giving warning before the arrival of a damaging ground motion at a site $[4,5]$. One of the prerequisites for disaster mitigation and management is the $a$ priori knowledge of impinging strong ground motion. EEW systems have also played an integral role in engineering applications. The main challenge for the effective use of EEW 
in engineering prospective is the longer response time taken by the structural control of buildings to activate on receiving EEW messages against strong shaking.

Possibility of getting maximum advantage of EEW system in Northern India is very high due to the fact that, for Northern India, potential source of earthquakes is located in Himalayas, whereas centers of large population as well as big industrial hubs (including our capital city Delhi) are in plains adjoining Himalayas. An EEW system for Northern India has been discussed in this study with an objective to estimate the lead time to some of the densely populated cities and to estimate the area encompassed for its advantages to reduce the disaster using this methodology. Delhi with more than 15 million inhabitants lies approximately $200 \mathrm{~km}$ from MBT and $300 \mathrm{~km}$ from MCT, the two most active thrust planes of the Himalayas. Many studies have been carried out to predict strong motion in Delhi [7-14]. Singh et al. [15] have calculated the values of PGA in Delhi for probable magnitude $M 8$ and M 8.5 earthquakes to be $96-140 \mathrm{~cm} / \mathrm{sec}^{2}$ and $174-218 \mathrm{~cm} / \mathrm{sec}^{2}$, respectively. Sharma et al. [16] proposed a maximum PGA of $0.34 \mathrm{~g}$ for Delhi. Delhi being the sociopolitical and economic nerve center of the country it demands much more attention from the angle of disaster preparedness such as EEW system.

EEW systems provide warnings of an impending damage either by rapid estimate of earthquake source parameters or based on simple thresholds. The warning time is generally few seconds to few tens of seconds depending on the distances between seismic source, seismic sensor, and user sites. The important objectives of EEW systems are event detection and location, magnitude estimation, peak ground motion prediction at the target site, and alert notification [17]. There are two types of EEW systems used around the world. First is front detection/regional warning system in which seismometers installed in the earthquake source area give early warnings to more distant area users. Second is an onsite warning system, which determines the earthquake parameters from the initial portion of the P-wave and predict the possible ground motion of the following S-wave at the same site. An onsite warning approach is considered to be fast as compared to regional warning approach but reliability of warning is better achieved in case of regional warning approach.

\section{Dataset}

The Northern part of the India is in the vicinity of Himalayas. The Himalayas are the result of continent-continent collision and account for approximately $15 \%$ of yearly global seismic energy release. The collision of Indo and Eurasian plates produced the Himalayas and the Tibetan Plateau which has the most noticeable topography in the world [18]. Minster and Jordan [19] estimated the northward motion of the Indian plate relative to the Asian plate as $42 \mathrm{~mm}$ /year in the western Himalaya. Later on the basis of geodetic plate model, higher convergence rate of $44 \mathrm{~mm} /$ year was observed from west to east Himalayan region $[20,21]$ and $54 \mathrm{~mm} /$ year towards North East [22]. It was concluded that the convergence was absorbed due to (i) shortening of sedimentary strata in the foreland as India underthrusts its cover rocks, (ii) contraction within the collision zone by uplift in the high Himalaya and reactivation of interior thrust faults, and (iii) crustal shortening via thickening of the crust and escapeblock tectonics along strike slip faults to the north of the collision zone $[23,24]$. The whole Himalayan belt (around 2,500 km) comprises many states like Jammu and Kashmir, Himachal Pradesh, Punjab, Harayana, Uttarakhand, Sikkim, Assam, Meghalaya, Arunachal Pradesh, Manipur, Mizoram, etc. which are thickly populated. The seismotectonic history of Himalaya reveals that there is a possibility of occurrence of large distributed earthquake with a recurrence interval $\leq 500$ years (similar to Kangra/Muzaffarabad earthquake) or a mega thrust type earthquake with a recurrence period $\geq 1000$ years as documented in the paleoseismological trenches $[16,25-$ 28].

Based on the past seismicity, seismic hazard, and other considerations which fall in line with the need of EEW system, the Northern Indian region has been selected as the case study to look for the need. This region is part of the seismic gap area between Kangra earthquake and BiharNepal earthquake and lies in Seismic Zone IV and V. The area for EEW was chosen based on geological and tectonic setting, past seismicity, and the location of important cities which are the target region for the EEW system to issue warnings [6].

The ongoing northwards drift of Indian plate makes Himalaya geo-dynamically active which has been studied extensively during the past few decades and the seismic hazard estimations made by considering such phenomenon have increased the hazard in long return periods [12, 25, 29-31]. Such conclusions tempt the scientists to work out remedies like EEW systems for risk reduction by estimation of magnitude, location of the impending earthquake, and providing warning time of few seconds before the catastrophic event hits the target site.

\section{EEW in Northern Indian Region}

EEW system works on the principal that the speed of seismic waves is much slower than the EM waves which are used to send the information of impinging seismic waves in much lesser time as compared to the arrival of actual seismic waves. Bhardwaj et al. [32, 33] described the working of the EEW system deployed in Northern India. Five EEW parameters, namely, maximum predominant period $\tau_{p}^{\max }$, average period of ground motion $\tau_{c}$, peak displacement $P_{d}$, cumulative absolute velocity CAV, and root sum of squares cumulative velocity RSSCV, were analyzed at 5 different time windows ( $1 \mathrm{sec}$ to $5 \mathrm{sec}$ ) and specified time domain amplitude level was estimated for issuing warning in minimum time interval and with reliable accuracy [6]. $\tau_{p}^{\max }$ is considered to be the first EEW parameter which utilizes first few seconds of Pwave to calculate the maximum possible predominant period within a selected time window $[34,35], \tau_{c}$ is the second EEW period parameter which is similar to $\tau_{p}^{\max }$ and was proposed by Kanamori [36]. It is different from $\tau_{p}^{\max }$ as follows:

(a) $\tau_{p}^{\max }$ is calculated from the ratio of velocity and acceleration records, while $\tau_{c}$ is calculated from the ratio of velocity and displacement records. 
TABLE 1: Calculated threshold values of different EEW parameter for issuing warning for an event having $M \geq 6$ at different time windows [6].

\begin{tabular}{|c|c|c|c|c|c|}
\hline \multirow{2}{*}{ Parameters } & \multicolumn{5}{|c|}{ Time Window } \\
\hline & $1 \mathrm{sec}$ & $2 \mathrm{sec}$ & $3 \mathrm{sec}$ & $4 \mathrm{sec}$ & $5 \mathrm{sec}$ \\
\hline$\tau_{p}^{\max }(\mathrm{sec})$ & 0.95 & 1.00 & 1.06 & 1.10 & 1.14 \\
\hline$\tau_{c}(\sec )$ & 1.02 & 1.17 & 1.20 & 1.42 & 1.55 \\
\hline$P_{d}(\mathrm{~cm})$ & 0.13 & 0.27 & 0.51 & 0.95 & 1.38 \\
\hline CAV (cm/sec) & 3.00 & 8.00 & 10.00 & 23.00 & 41.00 \\
\hline $\operatorname{RSSCV}(\mathrm{cm} / \mathrm{sec})$ & 0.30 & 1.00 & 1.70 & 5.20 & 10.00 \\
\hline
\end{tabular}

(b) $\tau_{p}^{\max }$ determines predominant period of the P-wave, while $\tau_{c}$ represents initial portion of P-wave over a fixed time window, i.e., the pulse width of $\mathrm{P}$-wave, and it varies according to the size of event, thus, used for estimating the event magnitude. Both $\tau_{p}^{\max }$ and $\tau_{c}$ parameters deal with the frequency content present in the initial portion of P-wave and when used together to estimate the magnitude, more accurate results were obtained [37]. Third EEW parameters are peak displacement parameter $\left(\mathrm{P}_{\mathrm{d}}\right)$; it is used to estimate the peak ground velocity (PGV), i.e., the damageability of the impending earthquake at a site [38-42]. Fourth EEW parameter is cumulative absolute velocity (CAV); it is defined as the integral of absolute value of ground acceleration over the seismic time history record. It is also defined as the area under the absolute accelerogram and includes the cumulative effects of ground motion duration. The velocity content present in the ground velocity record is found to be associated with the earthquake energy content of the recording site and also used to determine the damage threshold for engineered structures associated with the impeding earthquake [43], and fifth EEW parameter is root sum of squares cumulative velocity (RSSCV); it is calculated by taking root of the squared value of velocity vector calculated for a given time window. RSSCV is an EEW parameter which includes the cumulative effect (amplitude and time) of ground motion duration [32].

The dataset chosen by Bhardwaj et al. [6] was from KNET seismic array in Japan. Out of the whole data 1726 records of 105 events having $5 \leq \mathrm{M} \leq 7.2$ with epicentral distance $\leq 60 \mathrm{~km}$ were selected. To validate the developed algorithm in Indian conditions, the data was chosen from Himalayas. 28 Indian events were selected from these seismically active regions having 51 digital records from stations having epicentral distance up to $60 \mathrm{~km}$ from a range of magnitude varying between 3.3 and $6.8[10,30]$. To further validate the algorithm on worldwide data another dataset (not used for regression analysis in the study) was selected mainly from Southern California, Taiwan, and Turkey. The dataset consisted of 219 earthquake records of 14 earthquakes recorded at 174 strong motion stations with magnitude ranging $4.27 \leq \mathrm{M} \leq 7.62$ within $60 \mathrm{~km}$ of epicentral distance.

Regression relations were established between selected EEW parameters and magnitude to determine the threshold values for issuing warning for the events having $M \geq 6$.

The threshold values determined for different time windows [6] are shown in Table 1. Also, the calculated threshold values are found to be in good agreement with threshold values suggested by other researchers using considered EEW parameters at different dataset.

\section{Lead Time Calculation for Cities in Northern India}

Three EEW parameters preference based approach developed by Bhardwaj et al. 2015 [6] have been used in the present study to estimate the lead times. The stations used to estimate the lead time for various cities are shown in Figure 1. The cities chosen for estimation of lead time are given in Table 2 .

Lead time is defined as the time difference between Swave arrivals at the user site and first P-wave arrival at the seismic network in addition with the transmission delay and the time consumed in various processings (detection of P-onset, calculation of various EEW parameters, decision to issue an alarm for a potentially damaging earthquake). Figure 2 represents how the lead time is calculated in case of a regional warning approach.

The time taken by S-wave to reach a particular place will be time available to act or to give warning. Keeping in view, the developed EEW algorithm takes 4 sec to compute EEW parameters and to make decision about the alarm with $1 \mathrm{sec}$ of transmission delay and $1 \mathrm{sec}$ of processing delay. Thus, the lead time is calculated as follows:

$$
\begin{aligned}
& \text { Lead time }=(S \text {-wave arrival at the target city })-(P \text {-wave arrival at the farthest of } 4 \text { nearest EEW station } \\
& +4 \sec (E E W \text { algorithm })+1 \sec (\text { Transmission delay })+1 \sec (\text { Processing delay }))
\end{aligned}
$$

The lead time has been calculated for six main cities of Northern India, namely, Dehradun, Hardwar, Roorkee,
Muzaffarnagar, Meerut, and Delhi. The array of 100 stations with EEW sensors has been considered as the epicenter of 


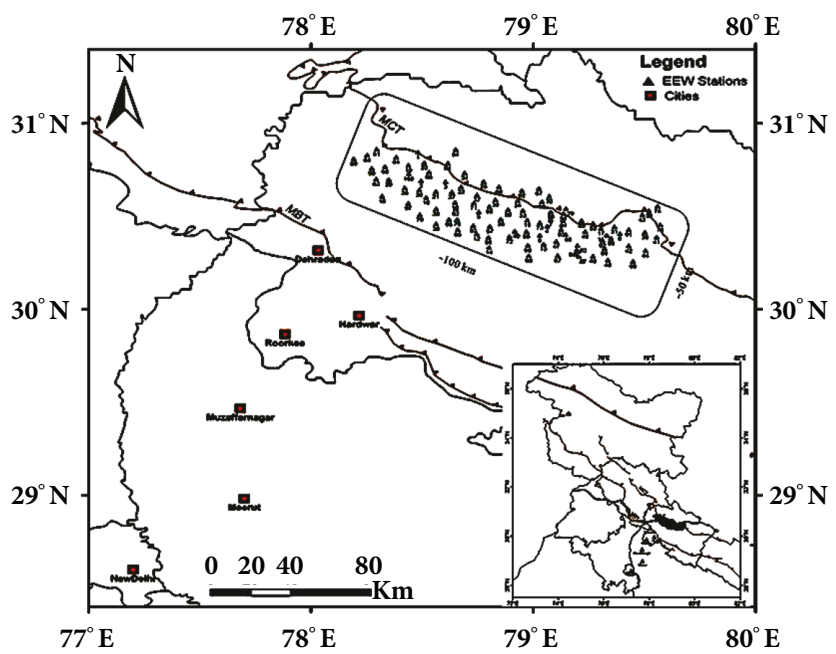

FIGURE 1: EEW instrumentation network in Uttarakhand region of Himalayas covering an area of around $5000 \mathrm{~km}^{2}$ which is used to estimate lead times. EEW stations marked with triangles and the benefited cities for which EEW will be issued are marked with solid squares.

TABLE 2: List of cities included for EEW system instrumentation and for issuing warning with their population, area, and population density information according to census 2011.

\begin{tabular}{|c|c|c|c|}
\hline Cities & Population & Area $\left(\mathrm{km}^{2}\right)$ & Population density (per $\mathrm{km}^{2}$ ) \\
\hline Uttarkashi & 329686 & 7951 & 41 \\
\hline Chamoli & 391114 & 7692 & 51 \\
\hline Rudraprayag & 236857 & 1896 & 125 \\
\hline TehriGarhwal & 616409 & 4085 & 151 \\
\hline Roorkee & 118188 & 33 & 3581 \\
\hline Dehradun & 1698560 & 3088 & 550 \\
\hline Hardwar & 1927029 & 2360 & 817 \\
\hline Saharanpur & 3464228 & 3689 & 939 \\
\hline Muzaffarnagar & 4138605 & 4008 & 1033 \\
\hline Meerut & 3447405 & 2522 & 1367 \\
\hline Baghpat & 1302156 & 1345 & 968 \\
\hline Ghaziabad & 4661452 & 1175 & 3967 \\
\hline Gautam Buddha Nagar & 1674714 & 1269 & 1320 \\
\hline Delhi & 16753235 & 1484 & 11289 \\
\hline
\end{tabular}

100 earthquakes having focal depth of $15 \mathrm{~km}$ originated in the selected seismic network region. The lead time for the six selected cities has been calculated for each earthquake by considering $\mathrm{P}$-arrival farthest from the nearest four stations and S-arrival at the cities along with decision time, transmission, and processing delay. The P-wave and S-wave velocities considered are $5.5 \mathrm{~km} / \mathrm{sec}$ and $3.2 \mathrm{~km} / \mathrm{sec}$, respectively. For example, for earthquake number 1 the nearest four stations are $1^{\text {st }}$ station itself, $23^{\text {rd }}$ station, $19^{\text {th }}$ station, and $61^{\text {th }}$ station, respectively (Figure 3), with corresponding hypocentral distances such as $15 \mathrm{~km}, 16.42 \mathrm{~km}, 17.29 \mathrm{~km}$, and $17.91 \mathrm{~km}$ as shown in Figure 4.

After the search of the nearest four stations with their hypocentral distance calculation being done, the longest Parrival time at the four nearest stations has been considered for calculating P-arrival time at the seismic network. Further, by using Heaversine's formula, distance between the event and the city has been determined and the time taken by the destructive S-wave to reach the particular city has been calculated. The calculated P-arrival and S-arrival time along with $4 \mathrm{sec}$ of EEW algorithm decision time, $1 \mathrm{sec}$ of transmission delay, and $1 \mathrm{sec}$ of processing delay provide the lead time for the cities by using (1). The lead time for each city has been calculated and shown in Figure 5. From Figure 5, it has been concluded that, for Dehradun, the minimum lead time is $5 \mathrm{sec}$ and maximum lead time is $37 \mathrm{sec}$, for Hardwar, the minimum lead time is $11 \mathrm{sec}$ and maximum lead time is $36 \mathrm{sec}$, for Roorkee, the minimum lead time is $20 \mathrm{sec}$ and maximum lead time is $47 \mathrm{sec}$, for Muzaffarnagar, the minimum lead time is $35 \mathrm{sec}$ and maximum lead time is $59 \mathrm{sec}$, for Meerut, the minimum lead time is $48 \mathrm{sec}$ and maximum lead time is $70 \mathrm{sec}$, and, for Delhi, the minimum lead time is $68 \mathrm{sec}$ and 


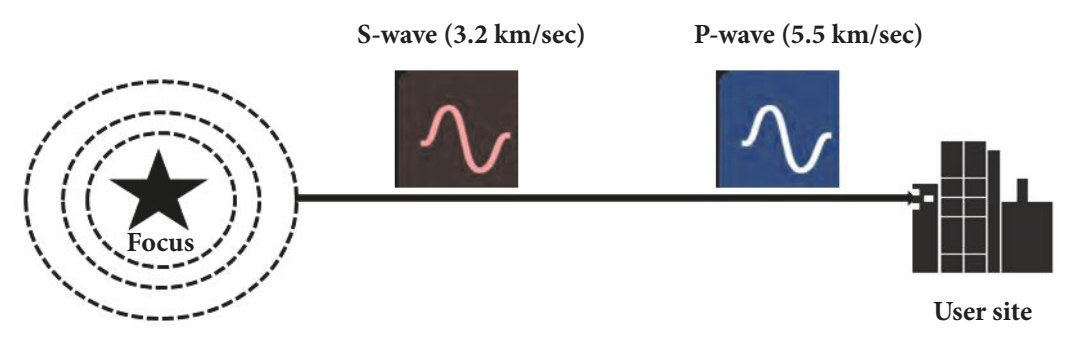

Lead time $=-$ wave arrival at the target-(first $P$-wave arrival at the network + Transmission time + Processing time

FIGURE 2: Difference in velocity of P-wave and S-wave used for lead time calculation.

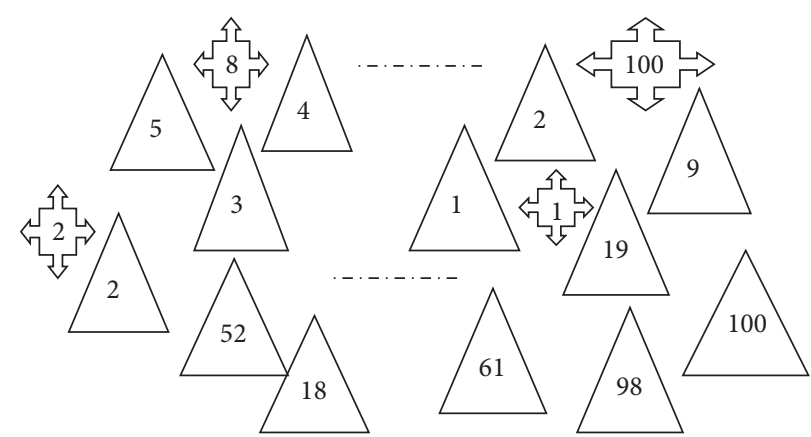

FIGURE 3: The possible arrangement of the proposed array of 100 earthquake stations and earthquakes in Uttarakhand region of Himalayas which is used to estimate lead times. EEW stations marked with triangles and the earthquakes by quad arrow.

maximum lead time is $90 \mathrm{sec}$ as shown in Figure 6. Thus, the cities which are near the epicentral region have small lead time in comparison with cities which are far from it. Calculating an average lead time for the considered cities is as follows:

(1) Dehradun, $20 \mathrm{sec}$

(2) Hardwar, 22sec

(3) Roorkee, $31 \mathrm{sec}$

(4) Muzaffarnagar, $44 \mathrm{sec}$

(5) Meerut, $57 \mathrm{sec}$

(6) Delhi, $76 \mathrm{sec}$

It is found that, for all the cities, the time available for alarm varies from $5 \mathrm{sec}$ to $90 \mathrm{sec}$, i.e., from seconds to more than a minute, which is substantial time to act for saving human lives and for activation of emergency response measures such as immediate shutdown of industrial units, nuclear power plants, gas lines, pipelines, computers, and slowing down high speed train. Further efforts are needed to achieve EEW system's amalgamation into engineering applications [43].

\section{Conclusion}

Advancement in data analyses techniques and increased public perception of seismic hazard accelerated the growth of real-time earthquake information system such as EEW system. The warning time provided by the EEW system can be used to minimize property damage and loss of lives and to aid emergency response. The EEW systems deployed in
Northern Indian region have been used as a case study. The multiparameter EEW algorithm has been used to calculate the lead time for Northern India cities such as Dehradun, Roorkee, Hardwar, Muzaffarnagar, Meerut, and Delhi.

The estimated lead time is defined as the time which consists of the time to reach S-wave at the target site after subtraction of the sum of $\mathrm{P}$-wave arrival time at the station, time taken by EEW algorithm, and processing time. Even though the time practically taken by the seismic wave is more, the time consumed in transmission and processing has to be subtracted which reduces the lead time which affects its usefulness in disaster mitigation measures. The study reveals that, for Dehradun, Hardwar, Roorkee, Muzaffarnagar, and Meerut, the minimum lead time is $5,11,20$, and 35 seconds while the maximum lead time is $37,36,47$, and $59 \mathrm{sec}$, respectively. One of the important outcomes of the study is the estimated lead time for Delhi which is minimum $68 \mathrm{sec}$ and maximum $90 \mathrm{sec}$. Such larger estimated lead times to these densely populated cities show that EEW can successfully work as one of the important real-time earthquake disaster reduction measures in Northern India. As the Himalayas have high seismicity runs with east-west trend for about $2500 \mathrm{~km}$ with the cities lying in southern vicinity (not more than $250 \mathrm{~km}$ ), such EEW systems are recommended to be deployed all along the southern flank of Himalayas.

\section{Data Availability}

The data used to support the findings of this study are available from the corresponding author upon request. 


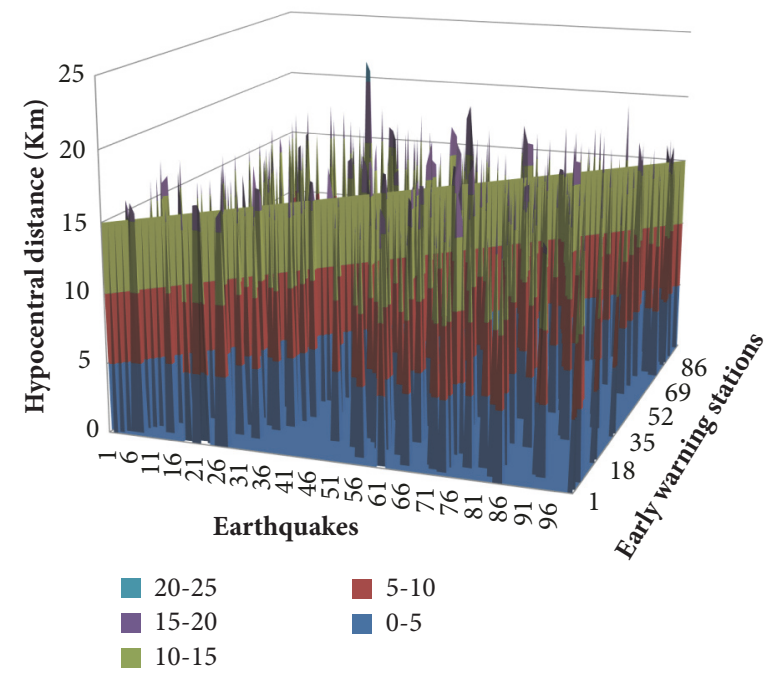

FIGURE 4: List of 100 earthquakes (EQ) with distribution of four nearest stations and their corresponding hypocentral distance (km).

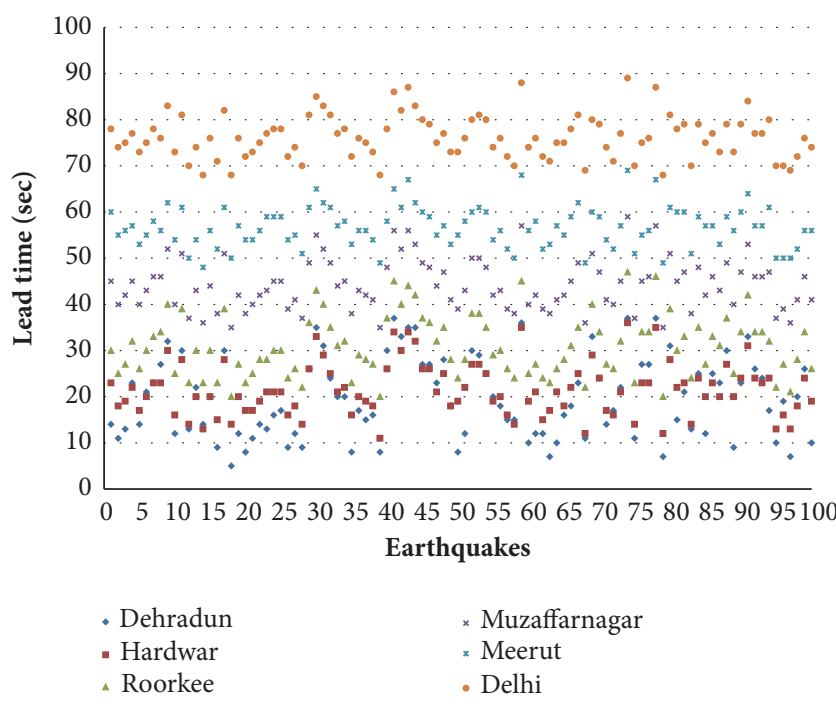

FIGURE 5: The calculated lead time for Dehradun, Hardwar, Roorkee, Muzaffarnagar, Meerut, and Delhi for the earthquakes (EQ) originated in the selected EEW seismic network region.

\section{Conflicts of Interest}

The authors declare that there are no conflicts of interest regarding the publication of this paper.

\section{Acknowledgments}

The authors would like to thank Ministry of Earth Science (MoES) of India and Professor Ashok Kumar, Department of Earthquake Engineering, Indian institute of Technology Roorkee, for his sincere support and invaluable advices for carrying out this study.

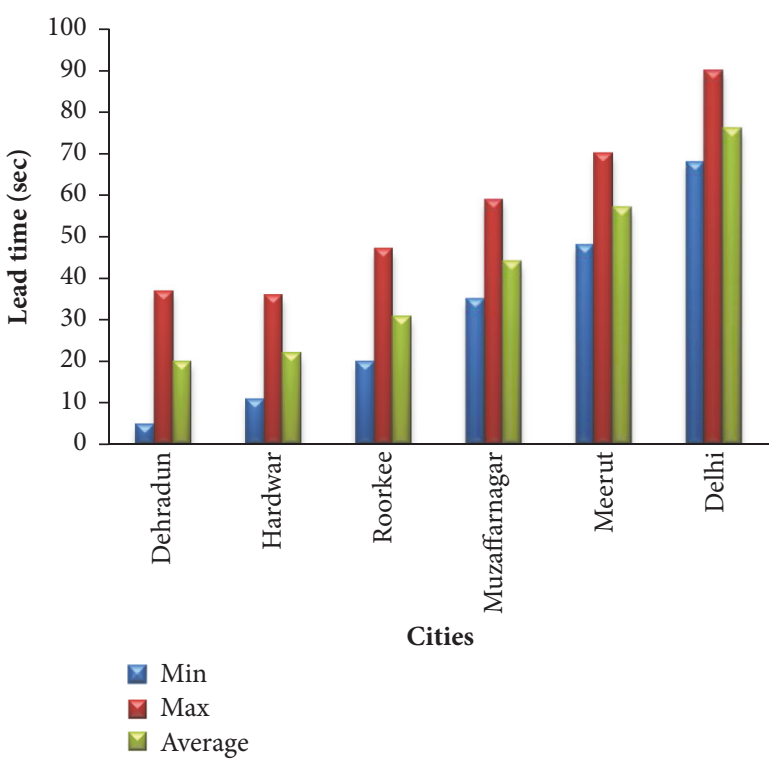

FIGURE 6: The maximum, minimum, and average lead time achieved using the proposed EEW algorithm for Dehradun, Roorkee, Hardwar, Muzaffarnagar, Meerut, and Delhi.

\section{References}

[1] A. K. Mahajan, J. J. Galiana-Merino, C. Lindholm et al., "Characterization of the sedimentary cover at the Himalayan foothills using active and passive seismic techniques," Journal of Applied Geophysics, vol. 73, no. 3, pp. 196-206, 2011.

[2] P. Kumari, A. Joshi, and M. L. Sharma, "Simulation of strong ground motion due to Mw 6.9 Sikkim earthquake using semiempirical forward modeling," in Proceedings of the Fifteenth Symposium on Earthquake Engineering, vol. I, pp. 44-50, 2014.

[3] P. Mandal, B. K. Rastogi, and H. K. Gupta, "Recent Indian Earthquakes," Current Science, vol. 79, pp. 1334-1347, 2000. 
[4] F. Wenzel and D. Lungu, "Earthquake risk mitigation in Romania," in Proceedings of the Euro Conference on Global Change and Catastrophe Risk Management II, Laxenburg, Austria, 2000.

[5] H. Kanamori, E. Hauksson, and T. Heaton, "Real-time seismology and earthquake hazard mitigation," Nature, vol. 390, no. 6659, pp. 461-464, 1997.

[6] R. Bhardwaj, M. L. Sharma, and A. Kumar, "Multi-parameter algorithm for Earthquake Early Warning," Geomatics, Natural Hazards and Risk, vol. 7, no. 4, pp. 1242-1264, 2016.

[7] M. L. Sharma, H. R. Wason, and R. Dimri, "Seismic zonation of the Delhi region for bedrock ground motion," Pure and Applied Geophysics, vol. 160, no. 12, pp. 2381-2398, 2003.

[8] G. C. Joshi and M. L. Sharma, "Estimation of peak ground acceleration and its uncertainty for northern Indian region," International Journal of Geotechnical Earthquake Engineering, vol. 2, no. 1, pp. 1-19, 2011.

[9] G. C. Joshi and M. L. Sharma, "Strong ground-motion prediction and uncertainties estimation for Delhi, India," Natural Hazards, vol. 59, no. 2, pp. 617-637, 2011.

[10] H. Mittal, A. Kumar, and R. Ramhmachhuani, "Indian National Strong Motion Instrumentation Network and Site Characterization of Its Stations," International Journal of Geosciences, vol. 3, no. 6, pp. 1151-1167, 2012.

[11] I. A. Parvez, G. F. Panza, A. A. Gusev, and F. Vaccari, "Strongmotion amplitudes in Himalayas and a pilot study for the deterministic first-order microzonation in a part of Delhi city," Current Science, vol. 82, no. 2, pp. 158-166, 2002.

[12] M. L. Sharma and M. K. Arora, "Prediction of seismicity cycles in the Himalayas using artificial neural network," Acta Geophysica Polonica, vol. 53, no. 3, pp. 299-309, 2005.

[13] M. L. Sharma and R. Dimri, "Seismic hazard estimation and seismic zonation of Northern India region for bed rock strong ground motion," Journal of Seismology and Earthquake Engineering, vol. 2, pp. 13-24, 2003.

[14] R. N. Iyengar, "Seismic status of Delhi megacity," Current Science, vol. 78, no. 5, pp. 568-574, 2000.

[15] S. K. Singh, W. K. Mohanty, B. K. Bansal, and G. S. Roonwal, "Ground motion in Delhi from future large/great earthquakes in the central seismic gap of the Himalayan Arc," Bulletin of the Seismological Society of America, vol. 92, no. 2, pp. 555-569, 2002.

[16] M. L. Sharma, "Seismic hazard in Northern India region," Seismological Research Letters, vol. 74, pp. 140-146, 2003.

[17] C. Satriano, L. Elia, C. Martino, M. Lancieri, A. Zollo, and G. Iannaccone, "PRESTo, the earthquake early warning system for Southern Italy: concepts, capabilities and future perspectives," Soil Dynamics and Earthquake Engineering, vol. 31, no. 2, pp. 137-153, 2011.

[18] S. K. Acharya and P. L. Narula, "Seismotectonic scenario of Himalaya and its recent developments," in Proceedings of the Eleventh Symposium on Earthquake Engineering, vol. I, pp. 319, 1998.

[19] J. B. Minster and T. H. Jordan, "Present-day plate motions," Journal of Geophysical Research: Atmospheres, vol. 83, no. B11, pp. 5331-5354, 1978.

[20] P. England and P. Molnar, "Active deformation of Asia: From kinematics to dynamics," Science, vol. 278, no. 5338, pp. 647650, 1997.

[21] Q. Wang, P.-Z. Zhang, J. T. Freymueller et al., "Present-day crustal deformation in China constrained by global positioning system measurements," Science, vol. 294, no. 5542, pp. 574-577, 2001.
[22] P. Mahesh, J. K. Catherine, V. K. Gahalaut et al., "Rigid Indian plate: Constraints from GPS measurements," Gondwana Research, vol. 22, no. 3-4, pp. 1068-1072, 2012.

[23] P. Molnar and P. Tapponnier, "Cenozoic tectonics of Asia: Effects of a continental collision," Science, vol. 189, no. 4201, pp. 419-426, 1975.

[24] P. Molnar and P. Tapponnier, "Relation of the tectonics of eastern china to the india-eurasia collision: Application of slipline field theory to large-scale continental tectonics," Geology, vol. 5, no. 4, pp. 212-216, 1977.

[25] M. L. Sharma and C. Lindholm, "Earthquake Hazard Assessment for Dehradun, Uttarakhand, India, Including a Characteristic Earthquake Recurrence Model for the Himalaya Frontal Fault (HFF)," Pure and Applied Geophysics, vol. 169, no. 9, pp. 1601-1617, 2012.

[26] N. Feldl and R. Bilham, "Great Himalayan earthquakes and the Tibetan plateau," Nature, vol. 444, no. 7116, pp. 165-170, 2006.

[27] R. Kumar, Earthquake Occurrence in India and Its Use in Seismic Hazard Estimation Using Probabilistic Methods [Phd thesis], Hemwati Nandan Bahuguna Garhwal University, Srinagar, India, 2006.

[28] S. Kumar, S. G. Wesnousky, T. K. Rockwell, R. W. Briggs, V. C. Thakur, and R. Jayangondaperumal, "Paleoseismic evidence of great surface rupture earthquakes along the Indian Himalay," Journal of Geophysical Research, vol. 330, pp. 3304-3309, 2006.

[29] D. Shanker and M. L. Sharma, "Estimation of seismic hazard parameters for the Himalayas and its vicinity from complete data files," Pure and Applied Geophysics, vol. 152, no. 2, pp. 267279, 1998.

[30] A. Kumar, H. Mittal, R. Sachdeva, and A. Kumar, "Indian strong motion instrumentation network," Seismological Research Letters, vol. 83, no. 1, pp. 59-66, 2012.

[31] M. L. Sharma and A. Tyagi, "Cyclic behavior of seismogenic sources in India and use of ANN for its prediction," Natural Hazards, vol. 55, no. 2, pp. 389-404, 2010.

[32] R. Bhardwaj, A. Kumar, and M. L. Sharma, "Root sum of squares cumulative velocity: An attribute for earthquake early warning," Disaster Advances, vol. 6, no. 3, pp. 24-31, 2013.

[33] R. Bhardwaj, M. L. Sharma, and A. Kumar, "Earthquake magnitude prediction for real time EEW system: An automization from P-wave time window analysis," Himalayan Geology, vol. 34, pp. 84-91, 2013.

[34] Y. Nakamura, "Development of the earthquake early-warning system for the Shinkansen, some recent earthquake engineering research and practical in Japan," in Proceedings of the Japanese National Committee of the International Association for Earthquake Engineering, pp. 224-238, 1984.

[35] Y. Nakamura, "On the urgent earthquake detection and alarm system (UrEDAS)," in Proceedings of the 9th World Conference on Earthquake Engineering, vol. 7, pp. 673-678, 1988.

[36] H. Kanamori, "Real-time seismology and earthquake damage mitigation," Annual Review of Earth and Planetary Sciences, vol. 33, no. 1, pp. 195-214, 2005.

[37] J. T. Shieh, Y.-M. Wu, and R. M. Allen, "A comparison of tau$\mathrm{c}$ and tau-p-max for magnitude estimation in earthquake early warning," Geophysical Research Letters, vol. 35, 2008.

[38] Y.-M. Wu and H. Kanamori, "Experiment on an onsite early warning method for the Taiwan early warning system," Bulletin of the Seismological Society of America, vol. 95, no. 1, pp. 347-353, 2005. 
[39] Y.-M. Wu and H. Kanamori, "Rapid assessment of damage potential of earthquakes in Taiwan from the Beginning of $\mathrm{P}$ waves," Bulletin of the Seismological Society of America, vol. 95, no. 3, pp. 1181-1185, 2005.

[40] Y.-M. Wu, H. Y. Yen, L. Zhao, B. S. Huang, and W. Liang, "Magnitude determination using initial P waves: a singlestation approach," Geophysical Research Letters, vol. 33, no. 5, 2006.

[41] Y.-M. Wu, H. Kanamori, R. M. Allen, and E. Hauksson, "Determination of earthquake early warning parameters, $\tau_{c}$ and $\mathrm{P}_{d}$, for southern California," Geophysical Journal International, vol. 170, no. 2, pp. 711-717, 2007.

[42] Y.-M. Wu and H. Kanamori, "Development of an earthquake early warning system using real-time strong motion signals," Sensors, vol. 8, no. 1, pp. 1-9, 2008.

[43] N.-C. Hsiao, Y.-M. Wu, L. Zhao et al., "A new prototype system for earthquake early warning in Taiwan," Soil Dynamics and Earthquake Engineering, vol. 31, no. 2, pp. 201-208, 2011. 

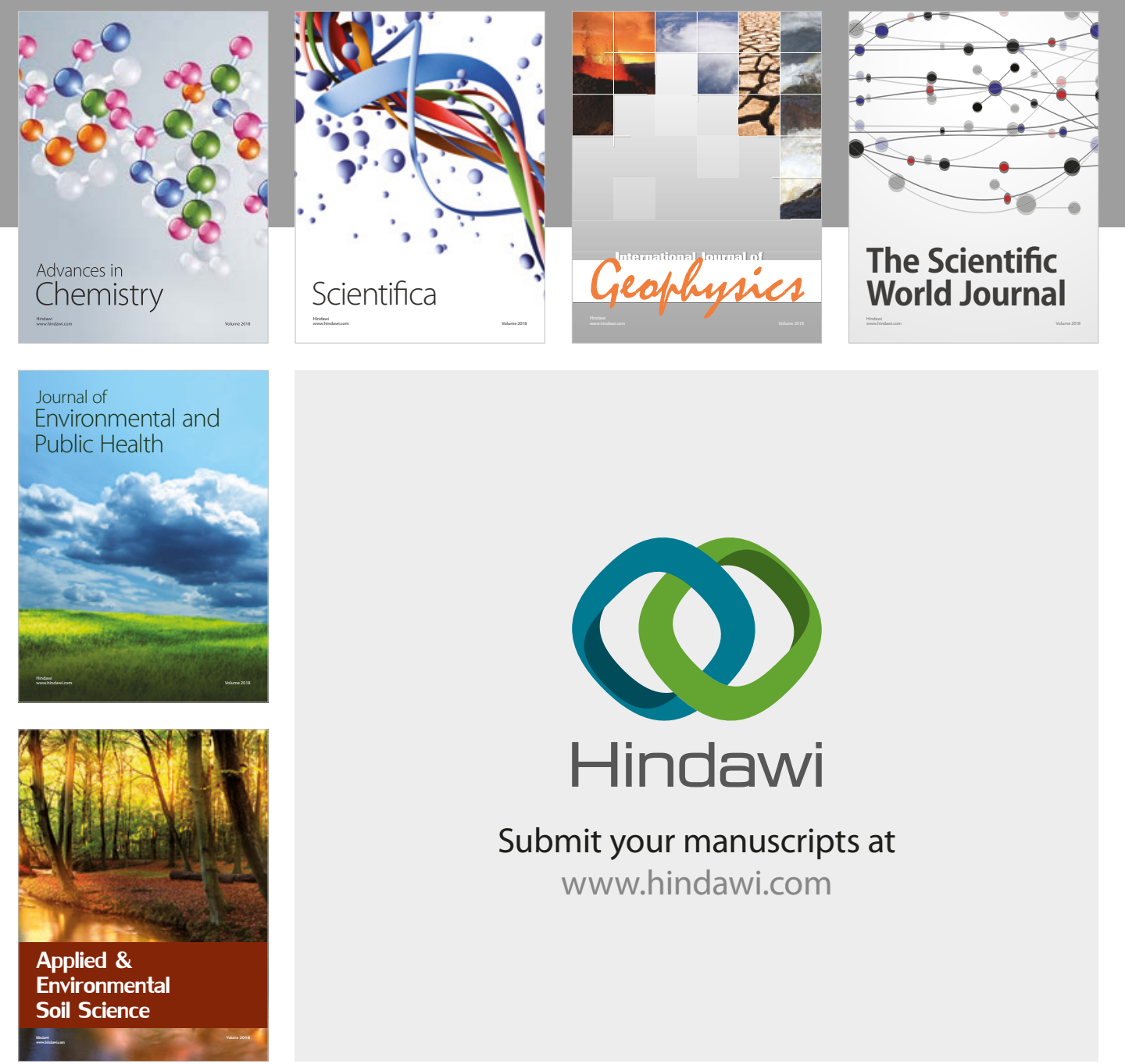

The Scientific

\section{World Journal}
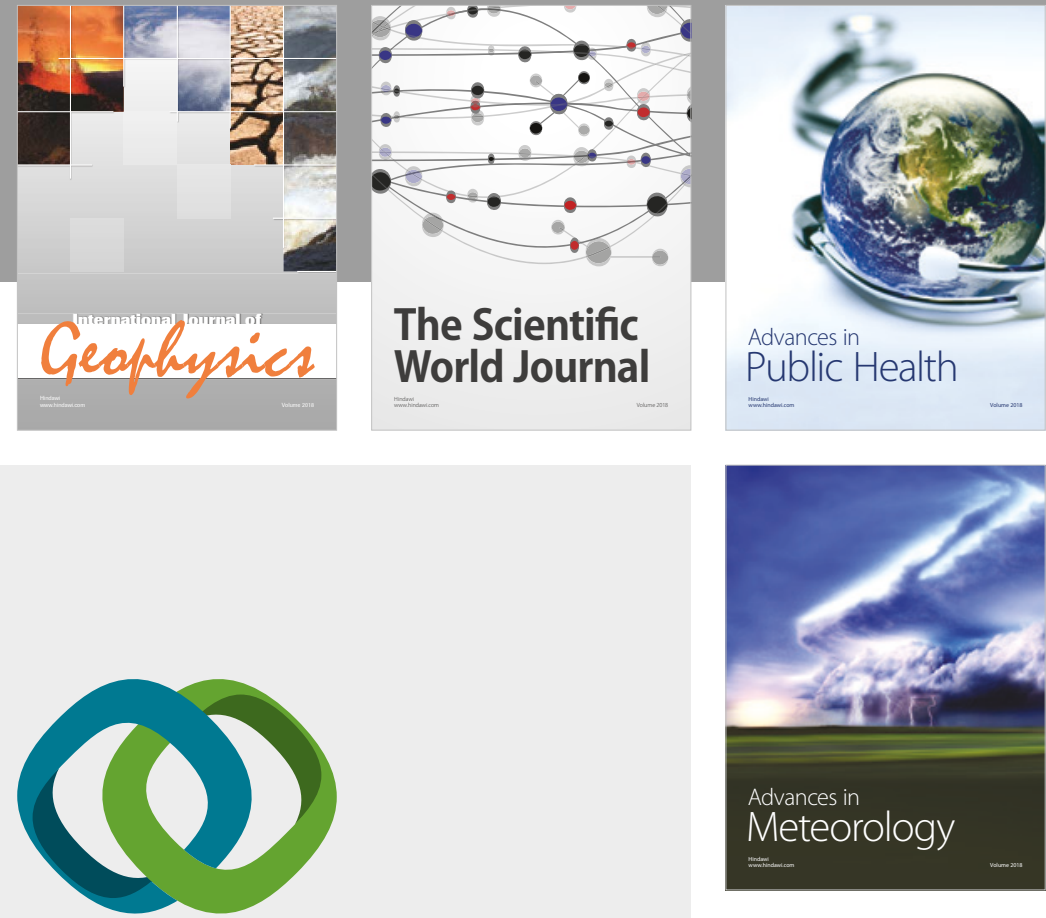

Advan

Public Health

\section{Hindawi}

Submit your manuscripts at

www.hindawi.com
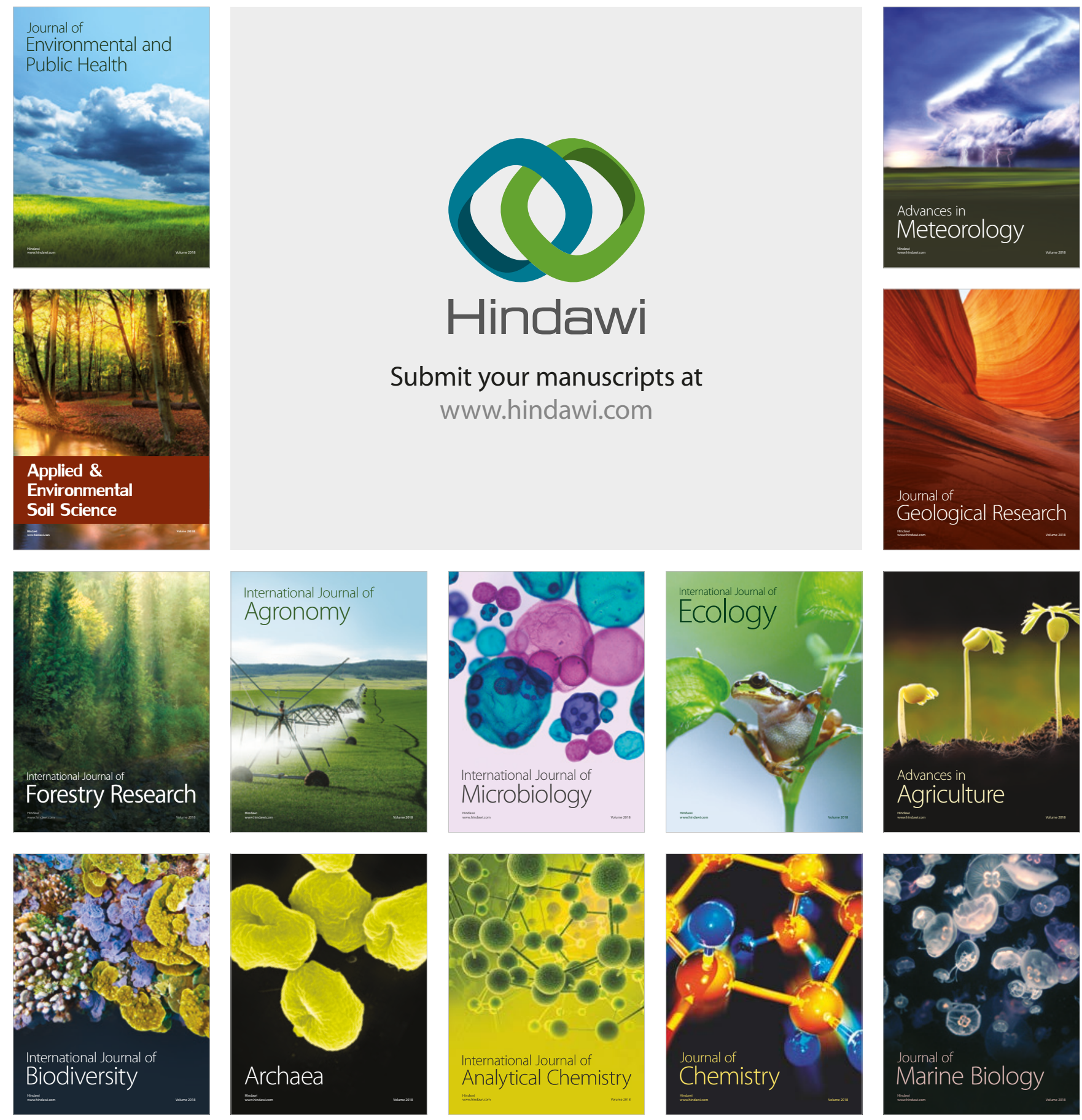